\title{
Retention in rural speech and language therapy: The impact of rural tertiary education in Australia
}

\author{
Michelle Smith-Tamaray ${ }^{\mathrm{a}, *}$, Sarah Verdon ${ }^{\mathrm{b}}$ and Laura Hoffman ${ }^{\mathrm{b}}$ \\ ${ }^{a}$ School of Allied Health, Australian Catholic University, Melbourne, Australia \\ ${ }^{\mathrm{b}}$ School of Allied Health, Exercise and Sports Sciences, Charles Sturt University, Albury, Australia
}

Received 30 June 2021

Accepted 22 November 2021

\begin{abstract}
.
BACKGROUND: Recruitment and retention of skilled health workers into rural areas is a major challenge to achieving equity in health between rural and urban populations.

OBJECTIVE: This study explored the impact of rurally-based tertiary education in promoting the recruitment and retention of speech and language therapists (SLTs) in non-metropolitan areas and intention to remain in the profession.

METHODS: Participants in this cohort study were 133 graduates from a rurally-based speech and language therapy course in Australia who completed the course between 1998 and 2018. Data were collected via an online survey. Data were analysed using inferential statistics, ArcGIS mapping software and content analysis in NVivo12.

RESULTS: $65.0 \%$ of the graduates practiced in rural or remote areas with just $21.1 \%$ practicing in major cities. Most participants' ideal work location was in a rural area. Benefits of rural practice included seeing a mixed caseload, living near family, work/life balance and loving their location. Challenges of rural practice included limited opportunities for specialist caseloads and career progression. In total, $93.2 \%$ of the rural graduates intended to remain in the speech and language therapy profession for the next 5 years.

CONCLUSIONS: This study indicates that SLTs who are trained in rural areas with a focus on servicing rural populations are highly likely to enter and remain in rural practice, consistent with the rural pipeline model.
\end{abstract}

Keywords: Retention, rural health, speech and language therapy, recruitment, higher education

\section{Introduction}

The disparities in health status between rural and urban populations are well documented internationally (e.g., Australian Institute of Health and Welfare, 2019; Cosby et al., 2019; Long et al., 2018; Wilson et al., 2020). Many countries including Australia, the USA, Canada and Ireland report that mortality rates, preventable diseases and avoidable

${ }^{*}$ Corresponding author: Michelle Smith-Tamaray, School of Allied Health, Australian Catholic University, Melbourne, Australia. E-mail: michelle.smith-tamaray@acu.edu.au. hospitalisations significantly increase with geographical remoteness (Council of Australian Governments Reform Council, 2012; Hartley, 2004; Johnson et al., 2011; Romanow, 2002). These findings are compounded by a higher proportion of socioeconomically disadvantaged residents and reduced access to health care services for those living in rural and remote communities (Bourke et al., 2012; Hartley, 2004). For the purposes of this study, the term 'rural' refers to inhabited areas outside of metropolitan regions. Geographically dispersed countries face further challenges to achieving equity in health between rural and urban populations given the complexities of 
providing high quality health services in isolated regions. One key strategy to address the rural-urban health disparity is to increase the availability and accessibility of health services in rural areas (Mason, 2013). To achieve this, a skilled rural health workforce is required to address the needs of rural populations. This is particularly true in the field of allied health, as many rural communities experience shortages of allied health professions confounded by difficulties in recruitment and high staff turnover (Humphreys et al., 2010). A review of the literature found that the strongest determinant for the intent to practice rurally is health professionals being of rural origin themselves (Katzenellenbogen et al., 2013). This is known as the 'rural pipeline model' (Tesson $\mathrm{G}$ et al., 2005). This model suggests that health professionals who originate and/or are trained in rural areas are more likely to be recruited and retained into practice in the rural health workforce (Durey et al., 2015). In keeping with this model, there have been increased calls for the training of health professionals in regional areas with the specific skill sets required to effectively serve rural populations.

\subsection{Speech and language therapy in rural areas}

Within the speech and language therapy profession, international researchers have found that people living outside of metropolitan regions face a number of barriers to service availability and accessibility (Lowe \& Nobriga, 2021; O'Callaghan et al., 2005; Verdon et al., 2011; Wilson et al., 2002). Specifically in Ireland, longer waiting times have been significantly associated with decreased speech and language therapy service utilisation (Curran, et al., 2015). To address this need, one rurally-based university in Australia has developed a speech and language therapy course that is specifically focused on preparing its graduates for rural and remote practice. Australia's vast geographical landscape and distribution of the population across the continent means that research into rural health workforce recruitment and retention is particularly important. The current study investigated the employment of graduates from this course over the 20 years since its inception to explore whether rurally-based speech and language therapy education resulted in (i) graduates practicing in rural areas; (ii) graduates' intention to remain in practice in rural areas, and (iii) graduates' intention to remain within the speech and language therapy profession itself.

\subsection{Retention of rural health professionals}

Retention refers to the length of time between commencement and termination of employment. Retention of allied health professionals in rural areas is a costly issue, both for employees and consumers. An international systematic review of workforce trends in rural allied health highlighted Australia as a leading country in the field of rural allied health research (Couch et al., 2021). Of the 22 studies included in the Couch et al. (2021) review, 18 were conducted in Australia. This review identified five themes that related to the retention of allied health professionals in rural areas across Australia, India, the USA and Canada. The themes were: (1) opportunities for career development, (2) clinical load, (3) organisational and workplace structure, (4) previous location exposure and (5) personal factors (Couch et al., 2021). Of these, three studies revealed that previous exposure to a rural location impacted retention in a rural area, with two studies indicating a positive impact and one indicating a negative impact (Devine, 2006; Manahan et al., 2009; Whitford et al., 2012). Both studies that identified personal factors as a positive driver of rural retention were related to knowing people in a rural area or being from a rural background (Devine, 2006; Manahan et al., 2009). However, none of these studies investigated the impact of a rural allied health education upon retention in rural practice.

A study undertaken in Victoria, Australia considered the retention of allied health workers in regional, rural, and remote areas and found that the median length of stay was just 2.7 years (Chisholm et al., 2011). Speech and language therapy had the third shortest length of stay out of the seven allied health professions included in the study, with a median stay of just over 2 years (Chisholm et al., 2011). Length of stay reduced further as remoteness of employment increased. The main reasons provided to employers for health professionals leaving rural positions were moving for their spouse's employment opportunities, working in isolation, and lack of career opportunities (Chisholm et al., 2011). The same study estimated that on average it costs $\$ 26,721$ (approximately US $\$ 14,500$ or $€ 16,700$ ) to recruit a new staff member in a regional, rural, or remote position. This includes both direct costs such as advertising and training and indirect costs such as reduced productivity among remaining staff members (Chisholm et al., 2011). Therefore, to ensure continuity of high-quality rural health services, retention of health professionals is essential. 


\subsection{Retention in the speech and language therapy profession}

International research has identified that retention of workers is an area of concern within the speech and language therapy profession (McLaughlin et al., 2010; Rossiter 2000; 2002). While limited data have been published regarding the retention of rural practicing speech and language therapists (SLTs) in Australia, data about the profession identify key issues around retention in the workforce. McLaughlin et al. (2010) found that Australian SLTs under the age of 34 years of age were more likely to leave the profession. Reasons for leaving include lack of career opportunities and professional development, being overworked and, therefore, having poor work/life balance, poor workplace relationships, poor management and lower than desired pay (McLaughlin et al., 2008; Rossiter, 2000). In contrast, research has identified enjoyable aspects of working as a SLT as the diverse and interesting nature of the work, engaging with clients, flexibility, providing a worthwhile service, the support and collegiality of working in a team, and continued learning (McLaughlin et al., 2008). Positive aspects of the job aid in the retention of SLTs. However, other reasons to stay in the profession that do not relate to job satisfaction have been highlighted including non-work responsibilities (i.e., family) and lack of alternative employment opportunities (McLaughlin et al., 2008; McLaughlin et al., 2010). McLaughlin et al. (2008) also found that negative aspects of a job (such as low pay) can be mitigated by positive aspects (e.g., flexibility for work/life balance) and thus lead to retention in positions. This is highly pertinent in the field of speech and language therapy which is largely female dominant $(97.5 \%$, Health Workforce Australia, 2014) and females in Australia (and around the world) disproportionately bear the workload of domestic and family commitments (Australian Institute of Family Studies, 2019).

\subsection{Development of rurally focused health professionals}

Given the strong data related to the rural pipeline model which shows students from rural areas are more likely to be recruited and retained in rural practice (Durey et al., 2015; Fisher \& Fraser, 2010), universities have developed fieldwork placements in rural areas to provide students with experiences of living and working in rural areas to identify whether this could have a similar impact upon student plans to work rurally as originating from a rural area (Brown et al., 2017; Playford et al., 2006). They found that recruitment of allied health graduates to rural and remote areas was high immediately post-graduation but tended to reduce over time (Brown et al., 2017), thus rural fieldwork placements aided in health workforce recruitment but not retention in rural areas.

The training of health professionals for rural practice has been acknowledged to require specific skills. However, it is also acknowledged that pinpointing the differences in practice is challenging. Bourke et al. (2004) identified five key concepts that were integral in the education of future rural health practitioners. These included explicitly teaching about the concepts of rural-urban health differentials, access to services, confidentiality within small communities, cultural safety and working within a team (Bourke et al., 2004). Although health professionals would argue that these concepts are important for any setting, when learning about working in rural communities they require additional focus. In addition, rural health workforce preparation also needs to have an emphasis on innovation and adaptability, to take on the challenges faced by the rural generalist clinician (Johnston \& O'Keefe, 2021).

While several universities have employed regional fieldwork placements, few have developed programs based in their entirety in rural areas and specifically focused on producing graduates who are equipped for rural practice. In the field of speech and language therapy, one rural university was the first to implement this approach in Australia, offering an undergraduate course to prepare speech and language therapy students for rural practice Verdon et al., 2022 forthcoming. The current study draws on data collected after the first 20 years of this program and is the first study to evaluate the impact of a rurally-based education in developing a rural speech and language therapy workforce in Australia, and the impact of rural training upon retention in both rural health and the speech and language therapy workforce in general.

\subsection{Aims}

This research aimed to investigate the impact of training SLTs in a rural setting by answering the following research questions:

1. Do graduates from a rural speech and language therapy course practice rurally? 
2. Where would graduates from a rural speech and language therapy course ideally like to work?

3. What factors influence their ideal practice scenario?

4. Does time since graduation impact whether SLTs are practicing in their ideal location?

5. Have graduates from this rural course remained practising as SLTs, why/why not?

6. Do graduates from a rural speech and language therapy course intend to remain practising as SLTs in the next 5 years?

\section{Method}

\subsection{Participants}

Participants in this study were 133 graduates of a rural Australian speech and language therapy program between 1998 and 2018. Since the commencement of this program 20 years ago, there have been approximately 500 graduates, therefore the sample represented approximately one quarter of the total population of graduates. Years since graduating ranged from one to 20 with an average of 8.5 years. All participants spoke English, and six (4.5\%) spoke an additional language, specifically: Bosnian (1), Cantonese (1), Croatian (1), Polish (1), Punjabi (1) and Urdu (1). Key demographic details are presented in Table 1.

The nature of the sample in this study was similar to the Australian speech and language therapy profession which in 2014 was reported to be $97.5 \%$ female, relatively young, with $93.2 \%$ of SLTs aged under 55 with just $0.2 \%$ identifying as Aboriginal or Torres Strait Islander (Health Workforce Australia, 2014). According to 2019 Speech Pathology Australia (SPA) membership data, $2.4 \%$ of members spoke a language other than English (Speech Pathology Australia, 2019). The authors recognise that accurate statistics regarding the Australian speech and language therapy profession are difficult to obtain. In this paper we draw on two key sources. First, the most recent Health Workforce Australia Data (2014) drawn from the Australian census which contains 5,295 SLTs, and second, the 2019 SPA membership data which contain 9,849 SLTs. The discrepancies in sample size show the fast rate of growth of the speech and language therapy profession and therefore the dynamic nature of national statistics. Furthermore, SPA membership data are a conservative snapshot of the profession as a whole with membership not compulsory in Australia.
Table 1

Demographics of the study sample

\begin{tabular}{|c|c|c|}
\hline Demographic & Number & Percent \\
\hline \multicolumn{3}{|l|}{ Sex } \\
\hline Female & 129 & $97.0 \%$ \\
\hline Male & 4 & $3.0 \%$ \\
\hline \multicolumn{3}{|l|}{ Age } \\
\hline 20 to 29 years & 59 & $44.4 \%$ \\
\hline 30 to 39 years & 68 & $51.1 \%$ \\
\hline 40 to 49 years & 4 & $3.0 \%$ \\
\hline 50 to 59 years & 2 & $1.5 \%$ \\
\hline $\begin{array}{l}\text { Aboriginal and or Torres Strait Islander } \\
\text { background }\end{array}$ & 2 & $1.5 \%$ \\
\hline \multicolumn{3}{|l|}{ Area of origin by ARIA* classification } \\
\hline Major city & 10 & $7.5 \%$ \\
\hline Inner regional & 34 & $25.6 \%$ \\
\hline Outer regional & 69 & $51.9 \%$ \\
\hline Remote & 3 & $2.3 \%$ \\
\hline Very Remote & 1 & $0.8 \%$ \\
\hline International & 2 & $1.5 \%$ \\
\hline Missing data & 14 & $10.4 \%$ \\
\hline \multicolumn{3}{|l|}{ Number of workplaces } \\
\hline 1 & 113 & $85.0 \%$ \\
\hline 2 & 18 & $13.5 \%$ \\
\hline 3 & 2 & $1.5 \%$ \\
\hline \multicolumn{3}{|l|}{ Caseload ${ }^{* *}$} \\
\hline Early childhood (0-5 years) & 80 & $60.2 \%$ \\
\hline Primary school (6-12 years) & 80 & $60.2 \%$ \\
\hline $\begin{array}{l}\text { High school / Adolescents ( } 13- \\
18 \text { years) }\end{array}$ & 59 & $44.4 \%$ \\
\hline Adults & 68 & $51.1 \%$ \\
\hline Aged (60+) & 41 & $30.8 \%$ \\
\hline \multicolumn{3}{|l|}{ Setting** } \\
\hline $\begin{array}{l}\text { Early childhood (Day care, } \\
\text { Pre-school) }\end{array}$ & 6 & $4.5 \%$ \\
\hline Early intervention & 7 & $5.6 \%$ \\
\hline Community Health & 17 & $12.8 \%$ \\
\hline School & 23 & $17.3 \%$ \\
\hline Hospital & 36 & $27.1 \%$ \\
\hline Rehabilitation & 2 & $1.5 \%$ \\
\hline Private practice & 29 & $21.8 \%$ \\
\hline NGO/Not for profit (unspecified) & 8 & $6.0 \%$ \\
\hline University & 3 & $2.6 \%$ \\
\hline Generalised/mixed caseload & 1 & $0.8 \%$ \\
\hline Disability & 6 & $4.5 \%$ \\
\hline Other & 2 & $1.5 \%$ \\
\hline
\end{tabular}

*Accessibility Remoteness Index of Australia (ARIA).

** Participants could work across multiple caseloads/settings.

\subsection{Data collection}

Data were collected via an online survey using Survey Monkey (SurveyMonkey Inc, 2018). The questionnaire was developed by the research team and was designed to investigate participants' experiences and perspectives regarding practice and retention in the speech and language therapy profession. The survey was piloted among graduates from the course to ensure that questions were logical and were able to capture the diversity of experiences 
of the graduate population. The online survey contained open and closed ended questions relating to the current and ideal practice locations and contexts of graduates from the rural speech and language pathology course. The survey contained a maximum of 67 questions which could be reduced by skip logic depending on the number of locations and positions a participant had practiced in since graduating. The survey was distributed via social media and professional online networks. Data were collected between July and September 2018. The current study drew upon the survey data to answer the research questions outlined in the aims section.

\subsection{Data analysis}

Data were analysed using the Statistical Package for Social Science Version 24 (IBM, 2018). Demographic data of participants and current occupation, workplace and ideal workplace scenarios were described using descriptive statistics. Postcode data were converted to Accessibility/Remoteness Classification of Australia (ARIA) classifications using the ARIA lookup tool (University of Sydney, 2019). The location of current and ideal workplaces were mapped using ArcGIS mapping software (ArcGIS Desktop 10.7.1). Inferential statistics were used to explore whether time since graduation impacted current work situation and future career intentions. Extended response data regarding ideal work scenarios (i.e., their ideal caseload and/or workplace type) and retention to the speech and language therapy workforce were analysed in NVivo Version 12 (QSR International, 2018) using an inductive content analysis (Lyon \& McAllister, 2019). Data for each question were analysed separately. Responses within each question were reviewed and grouped into preliminary open codes, then synthesised into categories related to each question. The primary author then coded all data according to these categories, and tallied responses to enable reporting of descriptive statistics. To enhance the dependability of findings, the initial categories were reviewed by the co-authors to check for reliability and consistency in interpretation (McAllister \& Lyon, 2019). Any disagreements in coding were discussed until consensus was met.

\subsection{Terminology}

The terms regional, rural, and remote are frequently used to describe non-metropolitan areas in Australia. In the current paper the (ARIA) clas-
Table 2

Current practice location of graduates from a regional Australian speech and language therapy program based on ARIA* classification

\begin{tabular}{lc}
\hline Current Practice Location (total $n=133)$ & Number $(\%)$ \\
\hline Major cities (Highly accessible) & $28(21.1 \%)$ \\
Inner regional (Accessible) & $46(34.6 \%)$ \\
Outer regional (Moderately accessible) & $40(30.1 \%)$ \\
Remote & $1(<1 \%)$ \\
Very remote & $0(0.0 \%)$ \\
International & $4(3 \%)$ \\
Missing data & $14(10.5 \%)$ \\
\hline
\end{tabular}

*ARIA (Accessibility Remoteness Index of Australia).

sification system (Hugo Centre for Migration and Population Health, 2020) was used to analyse data. This system classifies areas in Australia by five levels of remoteness based on road distance measurements to service centres categorised by population as explained in Table 2. Using this classification system, the university in the current study was based in an area classified as "inner regional", therefore we refer to the university as being in a regional area. However, when discussing health outside of metropolitan areas, this field is most commonly referred to in the literature as "rural health" and therefore, this terminology has been adopted when discussing the rural health workforce more broadly in the introduction and discussion of this paper.

\subsection{Ethics}

This research was approved by Charles Sturt University Human Research Ethics Committee, protocol number H18140. All participants provided informed written consent.

\section{Results}

\subsection{Practice location of regional speech and language therapy graduates}

The majority of the Australian-based participants (65\%) currently practised outside of major cities (see Table 2). Figure 1 describes the geographical distribution of graduates across Australia.

\subsection{Ideal practice location}

In addition to being asked their current practice location, participants were asked to identify their ideal practice location. Of the 102 participants who 


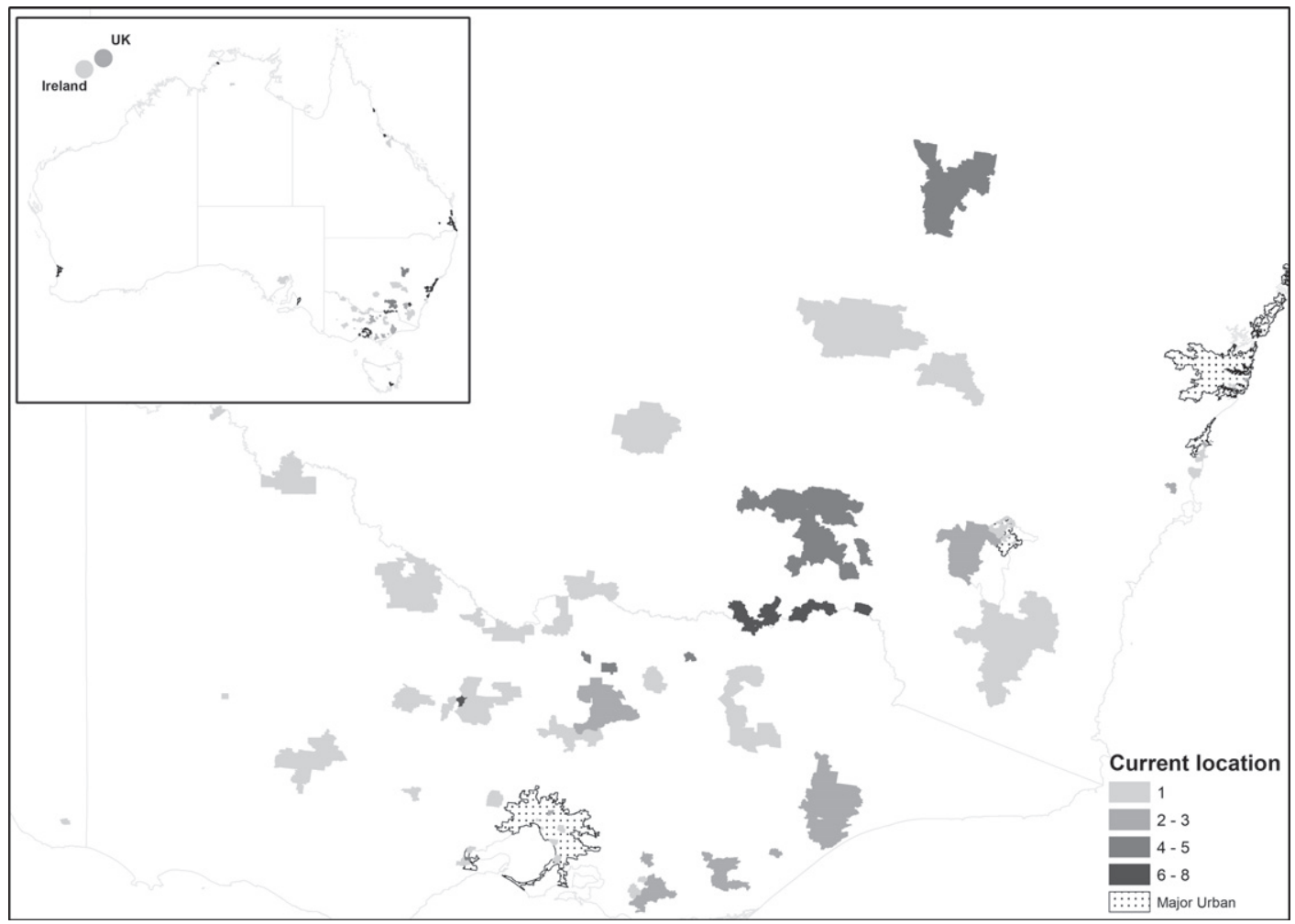

Fig. 1. Geographical distribution of graduates from the rural course across Australia.

Table 3

Participants currently in ideal practice location by ARIA classification $(n=102)$

\begin{tabular}{lc}
\hline Currently in ideal location & $57.8 \%(n=59)$ \\
Currently in ideal in Major city & $13.7 \%(n=14)$ \\
$\quad$ (highly accessible location) & \\
$\begin{array}{c}\text { Currently in ideal Inner regional } \\
\text { (accessible location) }\end{array}$ & $26.8 \%(n=27)$ \\
$\begin{array}{c}\text { Currently in ideal outer regional } \\
\text { (moderately accessible location) }\end{array}$ & $17.6 \%(n=18)$ \\
\hline
\end{tabular}

responded to this question, 59 respondents $(57.8 \%)$ stated that they were currently practising in their ideal location while 43 respondents ( $42.2 \%$ ) overtly stated a postcode that was different from their current location as their ideal practice location. Table 3 details the breakdown of ARIA categories where participants were currently practicing in their ideal location. Note that no participants reported that their ideal location was in a remote or very remote area.

Figure 2 illustrates the ideal practice location of participants. There were 67 participants $(65.7 \%)$ who stated that they felt their ideal location was rurally based. This meant that they were either currently based in their ideal location, and/or they responded that their ideal location was another rural location. Participants' ideal location was compared to their current location. Table 4 shows those participants who stated a postcode that differed from their current location, and how this was classified from an ARIA perspective. There were $48.8 \%$ of participants who reported a postcode different to their current one that was in the same ARIA classification. For example, someone who identified an Inner regional postcode then choose another Inner regional postcode as their ideal, despite them being different locations.

\subsection{Reasons for current location not being ideal}

Of the 43 participants who were not currently practising in their ideal location, 38 provided an explanation of why they were not in their ideal location. Some participants provided more than one reason, as these were open-ended responses. Reasons included a number of personal and work-related factors as reported in Table 5. 


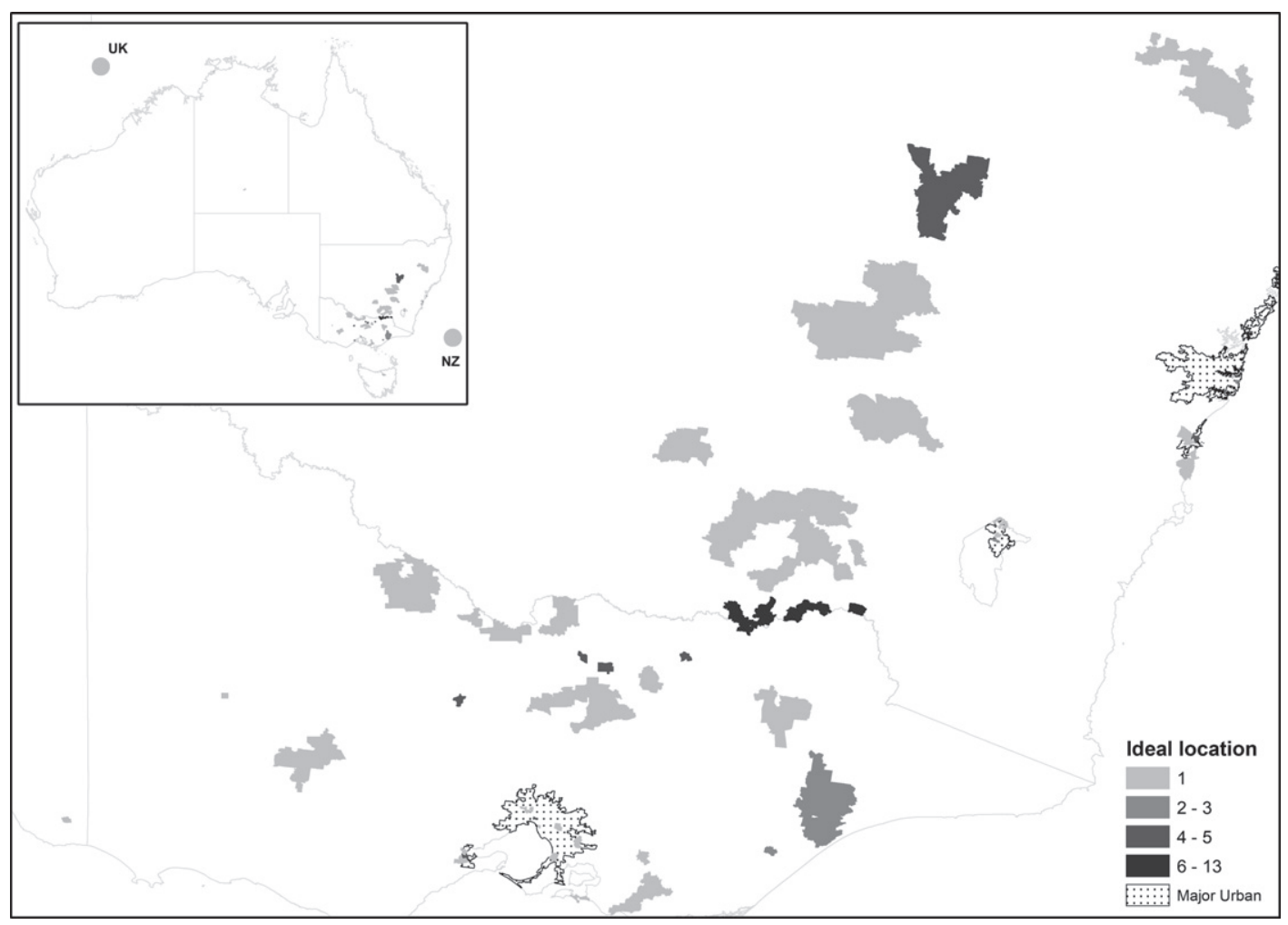

Fig. 2. The ideal practice location of participants.

Table 4

Comparison of current location and reported ideal location by ARIA classification

\begin{tabular}{lc}
\hline Current $\longrightarrow$ ideal & $\%(n=43)$ \\
\hline Inner/outer regional/remote $>$ Inner/outer & $48.8 \%(n=21)$ \\
$\quad$ regional & \\
Inner/outer regional > Major city/overseas & $27.9 \%(n=12)$ \\
Major city > Major city & $16.3 \%(n=7)$ \\
Major city $>$ outer regional & $4.7 \%(n=2)$ \\
Overseas $>$ overseas & $2.3 \%(n=1)$ \\
\hline
\end{tabular}

\subsection{Reasons for current location being ideal}

For those participants who responded that they are currently practising in their ideal geographical location, supporting open-ended comments related to both the reasons they felt this was their ideal location, but also things that would make the job itself better. Of the 59 participants who provided additional comments regarding the reason their current location was ideal, 29 reported that they love their current caseload, and three noted that they have good support in their current role. A further eight participants felt that their current job offered flexibility and good work-life bal- ance. However, seven participants said that although they love their job, they wish that they could work less hours to improve work-life balance. A further six participants stated that they would like to stay in the current location, but move into a different caseload or management; seven participants noted that although they want to stay in their current location, they felt that things could improve at their workplace in relation to service improvements. Table 6 illustrates the main reasons why participants felt their current location was ideal for them.

\subsection{Impact time since graduation upon whether SLTs are practicing in their ideal location}

A Wilcoxon rank sum test identified a statistically significant difference between the number of years since graduation, and a participant's satisfaction with their current location. People with more experience were more likely to be currently working in their ideal location than those with less experience $z=2.06$, $p=0.04$, with a small effect size $(r=0.2)$. The median years since graduation of those in their ideal location 
Table 5

Reasons current practice location is not ideal

\begin{tabular}{|c|c|c|}
\hline Category & Examples & $\%(n=38)^{1}$ \\
\hline Desire to be closer to home and family & $\begin{array}{l}\text { "It would be great to work closer to my residence and work fewer hours!" } \\
\text { (Rural based SLT) } \\
\text { "I would like to work closer to family (I am socially and geographically } \\
\text { isolated from them)." } \\
\text { (Rural based } S L T)\end{array}$ & $21 / 38(55.3 \%)$ \\
\hline Caseload//service delivery model & $\begin{array}{l}\text { "... if I could be a part of a health hub, that was more health promotion } \\
\text { focused, then that would be interesting. For example, a hub that has } \\
\text { playgroups, a library, parenting support, early intervention, maternal and } \\
\text { child health care... all integrated and well-resourced." } \\
\text { (Rural based SLT) }\end{array}$ & $20 / 38(52.6 \%)$ \\
\hline Work/life balance & $\begin{array}{l}\text { "I would like the hours to be flexible to meet the needs of my own family } \\
\text { while still providing and important service to the community." } \\
\text { (Rural based SLT) }\end{array}$ & $11 / 38(28.9 \%)$ \\
\hline Desire to move to a rural location & $\begin{array}{l}\text { "Love my current organisation, but do not want to be based in the city } \\
\text { (Major city based SLT) } \\
\text { Want to work in a rural area. Want to work for NSW health rather than a } \\
\text { private practice. } \\
\text { Would like to have a four day working week so I have time for other } \\
\text { pursuits such as helping on the farm." } \\
\text { (Rural based } S L T)\end{array}$ & $7 / 38(18.4 \%)$ \\
\hline $\begin{array}{l}\text { Desire to work in specialist caseload } \\
\text { (typically only available in } \\
\text { metropolitan areas) }\end{array}$ & $\begin{array}{l}\text { "Working with a team of clinicians in a fast paced and varied Critical Care } \\
\text { caseload." } \\
\text { (Major city based SLT) }\end{array}$ & $6 / 38(15.8 \%)$ \\
\hline Lack of support or team & $\begin{array}{l}\text { "Having a senior speech pathologist in the workplace within a } \\
\text { multidisciplinary team approach with a varying caseload." (Rural based } \\
S L T)\end{array}$ & $6 / 38(15.8 \%)$ \\
\hline Less red tape & $\begin{array}{l}\text { "More regional setting, and less of the NDIS targets, hurdles and } \\
\text { beaurocracy, in a trans/multidisciplinary team." } \\
\text { (Rural based } S L T)\end{array}$ & $4 / 38(10.5 \%)$ \\
\hline
\end{tabular}

${ }^{1}$ Participants could give more than one reason why their current location was not ideal.

Table 6

Reasons current practice location is ideal

\begin{tabular}{|c|c|c|}
\hline Category & Examples & $(\%) n=59^{1}$ \\
\hline Love current employment/caseload & $\begin{array}{l}\text { "Happy with current employment, love what I do } \bigcirc \text { " (Rural based } S L T) \\
\text { "Having exposure to all age ranges and working with all areas of Speech } \\
\text { Pathology practice." (Rural based SLT) }\end{array}$ & $29(49.2 \%)$ \\
\hline $\begin{array}{l}\text { Flexibility, work-life balance, close } \\
\text { to home }\end{array}$ & $\begin{array}{l}\text { "Extremely happy with current employment. Flexible hours, however still full time } \\
\text { employment. See a wide caseload of clients with varying complexities."(Rural } \\
\text { based SLT) }\end{array}$ & $8(13.6 \%)$ \\
\hline Good support in current role & $\begin{array}{l}\text { "My current position is ideal. Living near family, working for an organisation with } \\
\text { a great reputation, support, caseload I'm comfortable with but have opportunity } \\
\text { to develop in other areas."(Rural based } S L T)\end{array}$ & $3(5.1 \%)$ \\
\hline $\begin{array}{l}\text { Specifically stated that they love the } \\
\text { location }\end{array}$ & "Love my current position and location" (Rural based SLT) & $2(3.4 \%)$ \\
\hline
\end{tabular}

${ }^{1}$ Not all participants provided a reason for ideal.

was 9.1 years as compared with 5.5 years for those not in their ideal location.

\subsection{Regional graduates' intent to remain practising as SLTs in the next 5 years}

Participants were asked about their intent to continue practising as a SLTs for the next five years. Of the 121 responses to this question, the majority reported that they did intend to continue as SLTs $(92.6$
$\%)$. The main reasons participants offered in response to why they intend to stay in the profession in the next five years was around work and professional enjoyment of speech and language therapy, with $48.8 \%$ of participants stating that they "enjoy working as a speech pathologist" or that they "love" their job. Six specifically reported having a great team or workplace. A further $8 \%$ of participants reported being "passionate" about what they do and the caseloads they work with. 
When explaining why they enjoyed their work or were so passionate about it, many participants highlighted that job satisfaction and the sense of being able to make a difference really contributed to their enjoyment. This passion and enjoyment for the work being undertaken resulted in some participants $(5 \%)$ stating that they could not see themselves in any other profession; many felt that they still had more to offer the profession and their clients, particularly those who had only recently commenced in the profession. For some participants, the opportunities that the profession provides were a driving force in why they intended to continue in the profession. The diversity of roles within the profession and in rural practice, and the opportunity for moving into related roles (such as management or education) meant that there could be movement without retraining. Along with opportunity was the acknowledgement of the profession being flexible and having a good work-life balance (12\%). This was important as many participants reported that they had families or were intending to have families in the next 5 years $(8 \%)$.

Although most participants gave reasons related to job satisfaction, passion, enjoyment, opportunities, and work-life balance as their reasons for intent to stay in the profession for the next five years, some participants were more pragmatic in their reasoning. A number of participants wrote of a sense of obligation or commitment to stay. This was due to financial or legal obligations or having no current capacity to retrain for another profession. Financial reasons could be a positive (i.e., financial reasons were also listed along with enjoyment of position) or, alternatively the only reason for someone to continue. For most respondents though, it was the former, and three participants reported not being in a position to retrain or change careers. However, all three participants also stated that they did also enjoy their work.

\subsection{Reasons for not currently practising as a SLT or not intending to continue to practice}

Of the 133 participants surveyed, nine participants reported not currently working as an SLT. Those not practising as an SLT were aged between 20 and 39 years of age and were between one and 15 years post-graduation (mean 10.3 years). Positions currently being undertaken by those who were no longer practising as an SLT included student fieldwork placement coordinator $(n=1)$, social skills group facilitator $(n=1)$, clinical specialist in medical devices $(n=1)$, diversional therapist $(n=1)$, allied health manager $(n=1)$, academic $(n=1)$, home support assessor $(n=1)$ and, currently on parental leave $(n=2)$. Reasons given for not currently practicing as an SLT included limited financial or promotion opportunities $(n=2)$, limited SLT job opportunities in current location $(n=2)$, having a new opportunity arise $(n=1)$, not being able to justify retraining post parental leave $(n=1)$, and decreased interest or enjoyment in the job anymore $(n=2)$. One participant reported that they were 'disillusioned with the profession' due to a perceived shift in focus to consultancy based work and the rise of the "[National Disability Insurance Scheme] NDIS ... going to create many problems with regulation".

When asked if they would be working as an SLT in five years' time, nine participants stated that they did not intend to be working as an SLT. It should be noted that these were not all the same people who reported that they were not currently working as an SLT. Reasons provided for intent to leave the profession included "lost the passion" or enjoyment $(n=3)$, "career change", retraining $(n=3)$, and "related work" such as academia or student support $(n=3)$.

\section{Discussion}

This study is the first to examine the impact of a rural tertiary education upon retention in rural practice within the speech and language therapy workforce. The results from this study highlighted that a rurally-based course may produce graduates that can have an impact on recruitment and retention of SLTs to non-metropolitan locations. This study found that the majority of graduates from the rural course surveyed in this study $(65.0 \%)$ practiced in non-metropolitan areas. Most participants indicated that rural practice was their ideal work location. Benefits of rural practice included seeing a mixed caseload, living near family, work/life balance and loving their location. Challenges of rural practice included limited career opportunities for specialist caseloads and career progression. Those who had been graduated for longer were more likely to already be in their ideal practice location. In total, $93.2 \%$ of the rural graduates intended to remain in the speech and language pathology profession for the next 5 years. 


\subsection{The impact of rural tertiary education upon rural practice}

The data show that participants in this sample $(65.0 \%)$ are predominately practising in nonmetropolitan locations. The majority of these participants were practising in inner $(34.6 \%)$ or outer $(30.1 \%)$ regional areas. This is substantially higher than the national figures which indicate that $15.9 \%$ of Australian SLTs work in inner regional areas and $6.5 \%$ work in outer regional areas (Health Workforce Australia, 2014). These findings suggest that SLTs who are trained rurally may be more likely to practice outside of metropolitan areas than the Australian SLTs as a whole. The link between rural education and rural practice warrants further investigation.

Interestingly, less than $1 \%$ of participants in the current study reported practising in remote or very remote areas. This small percentage is reflective of the country's population, in which $2.1 \%$ lived in remote or very remote areas at the time of the 2016 census (Australian Bureau of Statistics, 2019), and the national speech and language therapy workforce as a whole, with $1.0 \%$ working in remote or very remote areas (Health Workforce Australia, 2014). However, when represented in terms of number of SLTs per capita, national workforce data show that in major cities there are 25.9 SLTs per 100,000 of population, whereas very remote areas have just 5.9 SLTs per 100,000 . This is concerning as the need for high quality health services is greater in more remote areas whose residents who have poorer health outcomes (Australian Institute of Health and Welfare, AIHW, 2019). For example, Australians living in remote areas are more likely to have a higher burden of disease, higher preventable hospitalisation rates as well as decreased access to health services and decreased life expectancy in comparison to Australians living outside of remote areas (AIHW, 2019). The findings of the current study are in keeping with a review of the Australian rural health workforce retention literature which found that health professionals were significantly less likely to be retained in remote areas in comparison to regional or rural centres (Russell et al., 2017).

\subsection{Ideal practice location for graduates from a rural speech and language therapy course}

Of the participants who responded to the question concerning ideal practice location, $57.8 \%$ were currently practicing in their ideal location. The vast majority of these participants were practising in inner or outer regional areas. This finding suggests that, not only did the graduates surveyed choose rural practice, they also enjoyed practicing rurally and did not wish to practice anywhere else. Such findings are extremely encouraging for the retention of these graduates in the rural health workforce. This finding contrasts with other tertiary education schemes which focus only on rural fieldwork placements. Such schemes found that engaging in rural fieldwork placements increased initial recruitment into the rural workforce (May et al., 2018), but did not always result in long term retention of health practitioners (Brown et al., 2017).

Data also show that SLTs currently practising in their ideal location was related to years of practice. Those who had been practising for longer were more likely to be in their ideal location than respondents who had less years of experience. This finding is consistent with data which suggest that although attrition is high for younger SLTs, once they have some experience they seem to be retained in the profession (McLaughlin, 2010). Humphreys et al. (2010) also noted in their study of rural allied health workforce in Victoria that older workers were less likely to leave a position. The link between increased age and retention in the rural workforce has been established in numerous studies (Daniels et al., 2007; Humphreys et al., 2010; Keane et al., 2011; Stagnitti et al., 2005) and the current findings are in support of this suggestion. It has been suggested that this may be due to younger professionals seeking further career opportunities and professional development that may not be available in rural areas (Campbell et al., 2012).

Reasons provided to support rural practice being an ideal location appeared to be mainly personal in focus. These included being close to family supports, having a shorter commute, having an improved worklife balance, and specifically wishing to work in a rural area. These findings are in keeping with several studies which have highlighted family and lifestyle as key motivating factors for retention in rural practice (Gallego et al., 2015; Keane et al., 2012). A review of incentives for rural health workforce retention by Campbell et al. (2012) found that a rural lifestyle and having family nearby were key incentives for remaining in rural practice. Furthermore, Keane et al. (2011) found that work/life balance was the most common reason given for rural allied health practitioners choosing their current role. However, some participants noted a complex interplay between being happy with their location and lifestyle, while being 
less satisfied with their job situation, and vice versa. Therefore, it is important to recognise that the lives of the rural health workforce are multifaceted and multiple factors across work and home life need to be considered to ensure retention in rural areas.

Given that the majority of participants originated from non-metropolitan areas, this personal drive to return to family and where they grew up is perhaps not surprising. A large body of literature has identified the link between coming from a rural background and deciding to practice rurally, even if this does not mean practicing in a person's hometown (Brown et al., 2017; Daniels et al., 2007; Laven \& Wilkinson, 2003). Furthermore, the university's focus on rural clinical education and specific skills for rural practice, as well as the university base being in a non-metropolitan area, may have provided further incentives for graduates to practice rurally (Brown et al., 2017; Daniels et al., 2007). These data are consistent with research undertaken looking at the rural pipeline model, which states that students who are from rural areas are more likely to want to practice in those areas post-graduation (Durey et al., 2015).

\subsection{Retention of rural SLT graduates in the profession}

From the 133 participants surveyed in this study, only nine were currently not practising as an SLT. This means that $93.2 \%$ of participants were currently practising as an SLT. Many of the alternative roles being undertaken by graduates were closely aligned to speech and language therapy clinical practice, suggesting that despite not being in a direct clinical role, the training received was being utilised in a similar field. Those who had left were an average of 10.3 years post-graduation and were all aged under 39 years of age, indicating that they had left the profession fairly early in their career. These findings are in some way similar to the findings of McLaughlin et al., (2010) who found that Australian SLTs aged under 34 years old were more likely to change jobs, but not leave the profession entirely.

Respondents in the current study reported a range of issues which led to not practising or wanting to practice. Some could not find a full time SLT role where they lived, while another had taken time out for maternity leave and could not justify the cost and time of engaging in the re-entry process. Other issues identified were in relation to pay issues and lack of career advancement. These findings are consistent with research undertaken by McLaughlin et al. (2008) who found that reasons identified for leaving the profession were often not related to the profession of speech and language therapy itself, but more towards the desire for career advancement and other opportunities. The sample in the current research suggested attrition of $6.8 \%$ from the profession. In comparison, McLaughlin et al. (2010) found that in their survey of 620 Australian SLTs, $13 \%$ were intending to leave the profession. Although the current sample was substantially smaller than the McLaughlin et al. (2010) study, the key demographic difference between the two samples was that all SLTs in the current study were trained in a rural area and the majority practiced in a nonmetropolitan area. Interestingly, in the McLaughlin et al. (2010), no significant difference was found in intention to leave a job or the profession based on whether an SLT lived in a rural or metropolitan area. The differences highlighted in the current study warrant further investigation as to whether retention rates to the speech and language therapy profession are influenced by undergoing tertiary education in a rural area.

For participants who intended to remain practising as SLTs, reasons surrounding job satisfaction and enjoyment were the major drivers in their decision. Many reported an enjoyment and passion for their job which made it worthwhile, despite the challenges. These data are consistent with McLaughlin et al. (2008) who reported that respondents in their study rated job satisfaction as being the primary driver for ongoing practice in the profession. In their study of 18 SLTs, doing a job that is "worthwhile" outweighed many stressors that may be present in the workplace. Similarly, Campbell et al., (2012) reported these "intrinsic" motivating factors as being an important component of retaining allied health professionals in rural areas. However, in their review of the literature, they also noted that extrinsic factors must also be considered (e.g., salary, job role etc.), as these can outweigh the intrinsic factors for some professionals.

\subsection{Limitations and future research}

While this study provides important insights into the impact of rurally-based tertiary education upon the retention of SLTs in both rural practice and in the profession in general, there are a number of limitations to be considered in the interpretation of these data. First, the limited sample size means that some demographics, such as SLTs in remote areas, are less represented in this study. Further research is 
needed to specifically investigate factors that support recruitment and retention of SLTs in remote practice locations. Future research may consider interviews or focus groups to obtain more in-depth exploration of the issues identified in this study. It is also noted that a large number of the participants in this study originated from non-metropolitan areas and, therefore, it is difficult to disambiguate whether it was being from a rural location or studying in a rural location that most impacted upon their engagement in the rural workforce. Future research may seek to specifically differentiate between these two factors as both have been found to impact likelihood of rural practice in the rural pipeline model. Participants chose to attend a regional university to study, therefore the participant group may reflect those who have a specific interest in rural speech and language pathology practice. This may have led to a biased, non-representative sample of SLTs.

\subsection{Implications for the speech and language therapy profession}

The findings of this study have implications for the tertiary sector in planning for the development of a sustainable and highly skilled rural health workforce. The participants in this study were trained in rural areas with specific skills for serving rural populations; their employment statistics reflected that the majority practice outside of metropolitan areas and this was both their current and desired place of practice. Interestingly, the findings of this study indicated that participation in the remote workforce was still low, even among rurally trained graduates. Future measures need to consider opportunities to increase both the skillset and desirability of working remotely. Given the large population of Aboriginal and Torres Strait Islander people living in remote Australia, is it important that allied health workers are well equipped to engage in culturally responsive practice when working remotely. As part of this consideration, is it essential to ensure that the diversity of the Australian speech and language therapy profession reflects the diversity of the Australian population, by facilitating the training of more SLTs from Aboriginal and Torres Strait Islander backgrounds, who have not only the professional skill set but also the cultural and linguistic knowledge to adequately support these communities. Furthermore, the intention of participants in the current study to remain as SLTs in the long term was far higher than figures considering the Australian speech and language therapy workforce as a whole. Therefore, rurally-based training in combination with a curriculum specifically designed for working with rural populations and being from a rural background, may provide a pathway to more satisfying work scenarios for SLTs and enhance retention rates within rural practice and the profession as a whole.

\section{Conclusion}

In conclusion, this study found that engaging in rural speech and language therapy education resulted in a high rate of participation in the rural health workforce. SLTs who were rurally trained had higher rates of actual and intention to both practice rurally and to remain in the speech and language therapy profession long term, in comparison to nationwide data. These findings have positive implications for the development of a committed and highly skilled rural speech and language pathology workforce.

\section{Acknowledgments}

Simon McDonald (SPAN mapping), Catherine Easton (survey development), Tana Cuming (research assistant) and Gail Fuller (survey development). The authors report no funding.

\section{Conflict of interest}

The authors have all worked for the university at which the course in this study is based.

\section{References}

Australian Institute of Family Studies. (2019). Work and family. https://aifs.gov.au/facts-and-figures/work-and-family

Australian Institute of Health and Welfare (2019). Rural and remote health. https://www.aihw.gov.au/reports/rural-remoteaustralians/rural-remote-health/contents/profile-of-rural-andremote-australians

Bourke, L., Humphreys, J.S., Wakerman, J., \& Taylor, J. (2012). Understanding rural and remote health: A framework for analysis in Australia. Health \& Place, 18(3), 496-503. https:// doi.org/10.1016/j.healthplace.2012.02.009

Bourke, L, Sheridan, C., Russell, U., Jones, G., DeWitt, D., \& Liaw, S. (2004). Developing a conceptual understanding of rural health practice. Australian Journal of Rural Health, 12, 181-186. https://doi.org/10.1111/j.1440-1854.2004.00601.x 
Brown, L., Smith, T., Wakely, L., Little, A., Wolfgang, R., \& Burrows, J. (2017). Preparing graduates to meet the allied health workforce needs in rural Australia: Short-term outcomes from a longitudinal study. Education Sciences, 7(2), 64. https:// doi.org/10.3390/educsci7020064

Campbell, N., McAllister, L., \& Eley, D. (2012). The influence of motivation in recruitment and retention of rural and remote allied health professionals: A literature review. Rural \& Remote Health, 12(3). https://doi.org/10.22605/RRH1900

Chisholm, M., Russell, D., \& Humphreys, J. (2011). Measuring rural allied health workforce turnover and retention: What are the patterns, determinants and costs?. Australian Journal of Rural Health, 19(2), 81-88. https://doi.org/10.1111/j.14401584.2011.01188.x

Cosby A.G., McDoom-Echebiri M.M., James W., Khandekar H., Brown W., \& Hanna H.L. (2019). Growth and persistence of place-based mortality in the United States: The rural mortality penalty. Am J Public Health, 109:155-162. https://ajph. aphapublications.org/doi/abs/10.2105/AJPH.2018.304787

Couch, A., Menz, H.B., Coker, F., White, J., Haines, T., \& Williams, C. (2021). Factors that influence workplace location choices in the different allied health professions: A systematic review. Australian Journal of Rural Health, 00, 1-12. 10.1111/ ajr.12768

Council of Australian Governments Reform Council. (2012). Healthcare 2010-11: Comparing outcomes by remoteness. COAG Reform Council.

Curran, A., Flynn, C., Antonijevic-Elliott, S., \& Lyons, R. (2015). Non-attendance and utilization of a speech and language therapy service: A retrospective pilot study of school-aged referrals. International Journal of Language \& Cотmиnication Disorders, 50(5), 665-675. https://doi.org/10.1111/ 1460-6984.12165

Daniels, Z.M.,VanLeit, B.J., Skipper, B.J., Sanders, M.L., \& Rhyne, R.L. (2007). Factors in recruiting and retaining health professionals for rural practice. The Journal of Rural Health, 23(1), 62-71. https://doi.org/10.1111/j.1748-0361. 2006.00069.x

Devine, S. (2006). Perceptions of occupational therapists practising in rural Australia: A graduate perspective. Australian Occupational Therapy Journal, 53(3), 205-210. http://doi.org/ 10.1111/j.1440-1630.2006.00561.x

Durey, A., Haigh, M., \& Katzenellenbogen, J.M. (2015). What role can the rural pipeline play in the recruitment and retention of rural allied health professionals? Rural \& Remote Health, 15(3). https://doi.org/10.22605/RRH3438

Fisher, K.A., \& Fraser, J.D. (2010). Rural health career pathways: Research themes in recruitment and retention. Australian Health Review, 34(3), 292-296. https://doi.org/10.1071/AH 09751

Gallego, G., Dew, A., Lincoln, M., Bundy, A., Chedid, R.J., Bulkeley, K.,... \& Veitch, C. (2015). Should I stay or should I go? Exploring the job preferences of allied health professionals working with people with disability in rural Australia. Human Resources for Health, 13(1), 53. https://doi.org/10.1186/ s12960-015-0047-x

Hartley D. (2004). Rural health disparities, population health, and rural culture. American Journal of Public Health, 94(10):1675-8. https://doi.org/10.2105/AJPH.94.10.1675

Health Workforce Australia. (2014). Australia's health workforce series: Speech pathologists in focus. Canberra, Australia: Author.
Hugo Centre for Migration and Population Health. (2020). Accessibility/Remoteness Index of Australia. https://www.adelaide. edu.au/hugo-centre/services/aria

Humphreys J., Chisholm M., \& Russell D. (2010). Rural allied health workforce retention in Victoria: Modelling the benefits of increased length of stay and reduced staff turnover. Victorian Department of Health.

Johnson, I.R., McDonnell, C., O'Connell, A.M., \& Glynn, L.G. (2011). Patient perspectives on health, health needs, and health care services in a rural Irish community: A qualitative study. Rural and Remote Health, 11(3), 12. https://doi.org/10.22605/ RRH1659

Johnston, E., \& O'Keefe, A. (2021). A toolkit to support working as a rural generalist. Speech Pathology Australia Conference [online].

Katzenellenbogen, J., Durey, A., Haigh, M., \& Woods, J. (2013). Critical success factors for recruiting and retaining health professionals to primary health care in rural and remote locations: Contemporary review of the literature. Rural Health West.

Keane, S., Lincoln, M., \& Smith, T. (2012). Retention of allied health professionals in rural New South Wales: A thematic analysis of focus group discussions. BMC Health Services Research, 12(1), 175. http://www.biomedcentral.com/1472$6963 / 12 / 175$

Keane, S., Smith, T., Lincoln, M., \& Fisher, K. (2011). Survey of the rural allied health workforce in New South Wales to inform recruitment and retention. Australian Journal of Rural Health, 19(1), 38-44. https://doi.org/10.1111/j.14401584.2010.01175.x

Laven, G., \& Wilkinson, D. (2003). Rural doctors and rural backgrounds: How strong is the evidence? A systematic review. Australian Journal of Rural Health, 11(6), 277-284. https:// doi.org/10.1111/j.1440-1584.2003.00534.x

Long, A., Hanlon, A., \& Pellegrin, K. (2018). Socioeconomic variables explain rural disparities in US mortality rates: implications for rural health research and policy. SSM Population Health, 6, 72-74. https://doi.org/10.1016/j.ssmph.2018. 08.009

Lowe, S.M., \& Nobriga, C.V. (2021). Head and neck cancer in a rural US population: Quality of life, coping, health care literacy, and access to services. American Journal of SpeechLanguage Pathology, 30(3), 1116-1133. https://doi.org/10. 1044/2021_AJSLP-20-00223

Lyons, R. \& McAllister, L. (2019). Methods in qualitative research in communication disorders. In R. Lyons \& L. McAllister (Eds.), Qualitative Research in Communication Disorders. J \& R Press.

Manahan, C., Hardy, C., \& MacLeod, M. (2009). Personal characteristics and experiences of long-term allied health professionals in rural and northern British Columbia. Rural and Remote Health, 9, 1238. https://doi.org/10.22605/RRH1238

Mason, J. (2013). Review of Australian Government Health Workforce Programs. Australian Government Department of Health.

May, J., Brown, L., \& Burrows, J. (2018). In-place training: Optimizing rural health workforce outcomes through Rural-Based Education in Australia. Education Sciences, 8(1), 20. https:// doi.org/10.3390/educsci8010020

McAllister, L. \& (2019). Lyons, R. Ensuring rigour in qualitative research. In R. Lyons \& L. McAllister (Eds.), Qualitative Research in Communication Disorders. J \& R Press. 
McLaughlin, E.G., Adamson, B.J., Lincoln, M.A., Pallant, J.F., \& Cooper, C.L. (2010). Turnover and intent to leave among speech pathologists. Australian Health Review, 34(2), 227233. https://doi.org/10.1071/AH08659

McLaughlin, E., Lincoln, M., \& Adamson, B. (2008). Speechlanguage pathologists' views on attrition from the profession. International journal of speech-language pathology, 10(3), 156-168. https://doi.org/10.1080/17549500801923310

O'Callaghan, A.M., McAllister, L., \& Wilson, L. (2005). Barriers to accessing rural paediatric speech pathology services: Health care consumers' perspectives. Australian Journal of Rural Health, 13(3), 162-171. https://doi.org/10.1111/j.14401854.2005.00686.x

Playford, D., Larson, A., \& Wheatland, B. (2006). Going country: Rural student placement factors associated with future rural employment in nursing and allied health. Australian Journal of Rural Health, 14(1), 14-19. https://doi.org/10.1111/j.14401584.2006.00745.x

Romanow R.J.Q. (2002) Building on values: The future of health care in Canada, Final Report. National Library of Canada: Commission on the Future of Health Care in Canada.

Rossiter, D. (2000). Leaving the profession. RCSLT Bulletin, 11-13.

Rossiter, D. (2002). Why SLT is a shortage profession. RCSLT Bulletin, 8-10.

Russell, D.J., McGrail, M.R., \& Humphreys, J.S. (2017). Determinants of rural Australian primary health care worker retention: A synthesis of key evidence and implications for policymaking. Australian Journal of Rural Health, 25(1), 5-14. https:// doi.org/10.1111/ajr.12294

Speech Pathology Australia. (2019). Speech Pathology Australia membership database. Melbourne, Australia: Author.
Stagnitti, K., Schoo, A., Reed, C., \& Dunbar, J. (2005). Retention of allied health professionals in south-west of Victoria. Australian Journal of Rural Health, 13, 364-5. https://doi.org/10.1111/ j.1440-1584.2005.00732.x

Tesson, G., Curran, V., Pong, R., \& Strasser, R. (2005). Advances in rural medical education in three countries: Canada, the United States and Australia. Rural and Remote Health, 5. doi.org/10.22605/RRH397

University of Sydney. (2019). ARIA lookup tool. https://www. pocog.org.au/aria/default.aspx

Verdon, S., Hoffman, L., Smith-Tamaray, M. (2022). Regional speech pathology education: Motivations and experiences. [manuscript in submission]

Verdon, S., Wilson, L., Smith-Tamaray, M., \& McAllister, L. (2011). An investigation of equity of rural speech-language pathology services for children: A geographic perspective. International Journal of Speech-Language Pathology, 13(3), 239-250. https://doi.org/10.3109/17549507.2011.573865

Whitford, D., Smith, T., \& Newbury, J. (2012). The South Australian Allied Health Workforce survey: Helping to fill the evidence gap in primary health workforce planning. Australian Journal of Primary Health, 18(3), 234-241. https://doi.org/ 10.1071/PY11027

Wilson, L., Lincoln, M., \& Onslow, M. (2002). Availability, access, and quality of care: Inequities in rural speech pathology services for children and a model for redress. Advances in Speech Language Pathology, 4(1), 9-22. https://doi.org/10.1080/ 14417040210001669191

Wilson, R., Rourke, J., Oamdasan, I., \& Bosco, C. (2020). Progress made on access to rural health care in Canada. Can Fam Physician, 66(1), 31-36. https://doi.org/10.4103/CJRM.CJRM 84_19 